\title{
Promoting Professional Nursing Practice through Critical Thinking and Attitudinal Change
}

\author{
${ }^{\circledR}$ Umar Aliyu, RN, BSc, MSc (N), PGDE, FWACN, ${ }^{\$}$ Otonoku K. Mathew, RN, RNA, \\ BNSc, MSc, ${ }^{\$}$ Rose Yayok Paul, RN, RM, Dipl. Dial, BNSc, PGDE, \\ \$Sherifat T. Shinaba, RN, RM, ADPA, BSc Oncology Nursing, PGDE, Fellow IAEA, \\ ${ }^{\$}$ Wosilat Romoke Oyewole, RN, RM, CAEN, BNSc and \\ $\$$ Mopelola Olabukun Olusanya, RN, RM, Dipl. Dial, BNSc \\ ${ }^{\$}$ Department of Nursing Services, National Hospital, Abuja - Nigeria
}

\begin{abstract}
This paper discusses the need to promote professional nursing practice through critical thinking and positive change in attitude towards new knowledge and global advancement. Central to the professional nursing practice is the ability of the nurse to think critically through the application of knowledge and experience, problem solving and decision making skills. Nurses use elements of reasoned thinking to meet the standards for intellectual thought which must be motivated to develop through the attitudes and dispositions of a fair-minded thinker. To reason effectively, nurses must develop skills and abilities essential for sound reasoning which may be affected by the attitude object which may change behaviour and actions. It is important that nurses possess attitudes that are generally commendable and foster improvement in service delivery. This must be seen in the thoughts, speeches and actions of the nurses.
\end{abstract}

Keywords: Nursing practice, Promote, Critical thinking, Attitudes, Behaviour change Quality care.

\section{Introduction}

The world's attention is turned to finding ways and means of getting health and health care to a greater number of people at a greater pace and at a reduced cost. It is also a time when nurses all over the world are taking both introspective and retrospective look at themselves and their profession (Bandman \& Bandman, 1995 ) with the view to improving the quality of nursing care that befits the $21^{\text {st }}$ century. Engaging in critical thinking is to provide directions and control in order to achieve professionalism.

Nursing as a profession exists in response to the needs of the society and holds ideals related to man's health throughout his life span. Nurses direct their energies towards the promotion, maintenance and restoration of health, the prevention of illness, the alleviation of suffering and the ensurance of peaceful death when life can no longer be sustained (International Council of Nurses, 1899 - 2009). The profession is concerned with holistic client care and all variables affecting an individual's response to stress. Nursing is also concerned with the wellbeing of an individual, family or community (Adejumo, Ilesanmi, Ofi, Oluwatosin, Okanlawon, Oyetunde, et al., 2011).

Nursing has gone through different evolutionary stages in its search for excellence from a technical service to a client-centered care that emphasizes the client, his rights and basic needs as an individual. Trends of development such as Nursing Audit and Evidence-Based Practice and concepts such as Nursing Process, Critical Analysis and Reasoning are introduced to improve the quality of nursing care and evaluate outcome of care (Mosby's Medical Dictionary, 2009, Mugford, Banfield \& O'Hanlon, 1991). Patient satisfaction and expectations of health care are indicative of quality health care needs. Thus, quality care has been designed to meet the irresistible and growing needs of the people and society at large (Wolff, Weitzel \& Fuerst, 1979). This can be achieved through critical thinking and positive attitude to the patients, work and others.

\section{Critical Thinking}

The ability to think critically through the application of knowledge and experience, problem solving and decision making skills is central to professional nursing practice (Paul \& Heaslip, 1995, Ford \& ProfettoMcGrath, 1994, Krammer, 1993). Critical thinking as a term has been over the years used interchangeably with concepts such as decision making, nursing process, problem solving, evaluation, critical analysis, judgement, reflection and reasoning (Oermann, \& Gaberson, 1998). To become a professional nurse requires that you learn to think like a nurse.

Nurses think differently from other health team personnel such as doctors, dentists, pharmacists, etc because of the way they view the client and the type of problems they deal with in practice when they engage in client care. To think like a nurse requires that we learn the content of nursing; the ideas, concepts and theories of 
nursing and develop our intellectual capacities and skills so that we become disciplined, self-directed, critical thinkers (Heaslip, 1993).

\section{Defining Critical Thinking}

In nursing, critical thinking for clinical decision-making is the ability to think in a systematic and logical manner with openness to question and reflect on the reasoning process used to ensure safe nursing practice and quality care (Heaslip, 1993). Critical thinking when developed in the practitioner includes adherence to intellectual standards, proficiency in using reasoning, a commitment to develop and maintain intellectual traits of the mind and habits of thought and the competent use of thinking skills and abilities for sound clinical judgements and safe decision-making (Heaslip, 1993).

\section{Intellectual Standards for Reasoning}

Practitioners in nursing who are critical thinkers value and adhere to intellectual standards (Paul, 1990, Norris \& Ennis, 1989, Ennis, 1985). As nurses, we want to eliminate irrelevant, inconsistent and illogical thoughts as we reason about client care.

\section{Elements of Reasoned Thinking}

All thinking in nursing, if it is purposeful, involves eight elements (Paul, 1990):-

1. The problem, question, concern or issue being discussed or thought about by the thinker. What the thinker is attempting to figure out.

2. The purpose or goal of the thinking. Why we are attempting to figure something out and to what end. What do we hope to accomplish?

3. The frame of reference, points of view or even world view that we hold about the issue or problem.

4. The assumptions that we hold to be true about the issue upon which we base our claims or beliefs.

5. The central concepts, ideas, principles and theories that we use in reasoning about the problem.

6. The evidence, data or information provided to support the claims we make about the issue or problem.

7. The interpretations, inferences, reasoning, and lines of formulated thought that lead to our conclusions.

8. The implications and consequences that follow from the positions we hold on the issue or problem.

When nurses reason they use these elements of thought to figure out difficult questions and recognize that their thinking could be flawed or limited by lack of in-depth understanding of the problem at hand. Therefore, they critically monitor their thinking to ensure that their thinking meets the standards for intellectual thought (Bandman \& Bandman, 1995, Paul\& Heaslip, 1995).

\section{Intellectual Traits and Habits of Thought}

To develop as a critical thinker one must be motivated to develop the attitudes and dispositions of a fair-minded thinker. That is, one must be willing to suspend judgments until one truly understands another point of view and can articulate the position that another person holds on an issue. Nurses come to reasoned judgments so that they can act competently in practice. Critical thinkers in nursing are truth seekers and demonstrate open-mindedness and tolerance for others' views with constant sensitivity to the possibility of their own bias. Nurses' who are critical thinkers value intellectually challenging situations and are self-confident in their well reasoned thoughts. To reason effectively, nurses have developed skills and abilities essential for sound reasoning (Heaslip, 1993).

\section{Critical Thinking Skills and Abilities}

Critical thinkers in nursing are skillful in applying intellectual skills for sound reasoning.

These skills have been defined as information gathering, focusing, remembering, organizing, analyzing, generating, integrating and evaluating (Registered Nurses' Association of British Columbia, 1990). All acts in nursing are deeply significant and require a mind fully engaged in the practice of nursing and the right attitude. Critical thinking is a composite of: -

(1) Attitudes of inquiry that involve an ability to recognize the existence of problems and an acceptance of the general need for evidence in support of what is asserted to be true;

(2) Knowledge of the nature of valid inferences, abstractions, and generalizations in which the weight or accuracy of different kinds of evidence are logically determined; and

(3) Skills in applying the above attitudes and knowledge (Watson \& Glaser, 1980). 


\section{Attitude Model}

Attitudes are developed on the ABC model (affect, behavior, and cognition).

The affective component is an emotional response that expresses an individual's degree of preference for an entity. For instance, if there is a patient you think is dirty looking you might feel uncomfortable when you interact with him or her.

The behavioral component is a verbal indication or typical behavioral tendency of an individual. For instance, if you nurse a patient you like on the ward then you might spend all your free time listening and tending to him or her. The attitude object has changed your behaviour and actions.

The cognitive component is a cognitive evaluation of the entity that constitutes an individual's beliefs about the object. For instance, you might like a patient because he or she cooperates in the execution of treatment plans. You might also believe that the patient is a lot like you are which makes nursing care easier to deliver.

Note most attitudes are the result of either:-

$>$ Direct experience or

$>$ Observational learning from the environment.

\section{Attitude}

An attitude is a hypothetical construct that represents an individual's degree of like or dislike for something. Attitudes are generally positive or negative views of a person, place, thing, or event - this is often referred to as the attitude object. People can also be conflicted or ambivalent toward an object, meaning that they simultaneously possess both positive and negative attitudes toward the item in question.

\section{Attitudinal Change}

Attitudinal change implies that questionable opinions or feelings towards health care (health care consumers, their relatives, work, healthcare professionals, government etc.) are changed with ones that are generally commendable and fosters improvement in service delivery (Roter, Frankel, Hall \& Sluyter, 2006, Ambady, Rosenthal, Winograd, 2002). It offers ways of thinking, and responding both personally and professionally.

It is natural for people's values and beliefs to differ within and across social and cultural groups. Nurses will encounter many situations in which their own cultural values and beliefs differ from those of clients and other professionals (Lomas \& Haynes, 1987). It is therefore our responsibility as Nurses to consciously identify these differences and ensure that they do not stand in the way of nursing care (Cervarom, 1985).

Nursing is both an art and a science. The service in caring for patients is the art and the competency (skill, knowledge and attitude (Smith, 2008) in providing quality care is the science. It is observed (Nutt, 2009) that the changing demands in health care have resulted in a significant demand for Nurses who have advanced knowledge and clinical expertise in assessment, diagnosis, treatment, and health care management. This ensures wide-ranging and constant care to patients in a variety of health institutions.

Attitude can be influenced by what is happening in a person's life, e.g. previous experiences, interactions with providers of health care, etc (Veronica, Ernest, Eric \& Duah, 2011). When people have health issues they are vulnerable, and the negative attitudes (John, 2007) of health professionals towards them compound their vulnerability. As Nurses we are agents of change and we must be seen to be so in our thoughts, speeches and actions.

For Nursing in Nigeria to earn the respect of other health care professionals and the care consumers, a completely new healthy attitude is required. Effective communication plays a vital role (Amewonye \& Davies, 2011) in attitudinal change; we need to develop effective communication skills and positive working relationships (Amewonye, et al., 2011) to improve our services. Negative attitudes crops up unconsciously, the person involved may or may not be aware of such. But the people who feel the impact of our attitude on their lives often are pointers to these unprofessional behaviors. Self-awareness is important for the Nurse when communicating with others.

Your attitude toward others no matter their state of mind will tell who you are and the type of attitude within you. Aside from social etiquette, there is need for change in attitude towards new knowledge and global advancement (Ehiemere, 2009). The contemporary things about health care now is advanced technological innovations and concern about staff in terms of their cohesiveness, commitment and the kind of rapport they have amongst them.

\section{Conclusion}

In order to promote professional nursing practice through critical thinking and positive change in attitude, professional Nurses must rise up to the challenges of the $21^{\text {st }}$ century. These embrace reforms especially in the health sector in which Nursing domain can be identified as there are changing health needs and societal expectations which demand for professional competency geared towards establishing high quality care. Nurses 
are required to reason about nursing by reading, writing, listening and speaking critically. This will enable them think critically about nursing and ensure that they gain in-depth knowledge about nursing as a practice profession.

\section{References}

[1]. Adejumo, P. O., Ilesanmi, R. E., Ofi, A. B., Oluwatosin, O. A., Okanlawon, F. A., Oyetunde, M. O., Odetola, T. D., Ndikom, M. C., Awonuga, O. \& Ojewale, L. C. (2011). An overview of consultant nursing specialist in clinical practice in Nigeria. West African Journal of Nursing, 22(2): $76-82$

[2]. Ambady, N., Rosenthal, R., \& Winograd, C. H. (2002). Physical Therapists' Nonverbal Communication Predicts Geriatric Patients' Health Outcomes. Psychology and Aging. American Psychological Association, 17(3): 443 - 452

[3]. Amewonye, F. \& Davies, A. E. (2011). Registered Nurses' perception on the use of nonverbal communicative skills in Nursing. West African Journal of Nursing, 22(2): 66 - 77

[4]. Bandman, E.L., \& Bandman, B. (1995). Critical thinking in nursing. Norwalk, CN: Appleton and Lange.

[5]. Cervaro R. M. (1985). Continuing professional education and behavioural change: a model for research and evaluation. J Contin Educ Nurs; 16:85-8.

[6]. Ehiemere, I.O. (2009). Current trends in Nursing education, research and practice. West African Journal of Nursing, 20 (2): 87 -93

[7]. Ennis, R. H. (1985). A logical basis for measuring critical thinking skills. Educational Leadership, 43, 44 - 48.

[8]. Ford, J., \& Profetto-McGrath, J. (1994); A model for critical thinking within the context of curriculum as praxis. Journal of Nursing, 33(8), 341-344.

[9]. Heaslip, P. (1993). Revised 2008 Thompson Rivers University, Box 3010, 900 McGill Road, Kamloops, BC Canada, V2C 5N3 pheaslip@tru.ca

[10]. International Council of Nurses (ICN), (1899 - 2009). ICN advancing Nursing and Health World wide. www.icn.ch/definition.html

[11]. John, M. E. (2007). Declining Nursing Delivery in Nigeria: A challenge to Nurse Leaders. A paper presented at the $11^{\text {th }}$ edition of the Continuing Professional Development Programme for Heads of Nursing Services. September, 2007

[12]. Krammer, M. (1993). Concept clarification and critical thinking: An integrated process. Journal of Nursing Education, 32(9), 406414.

[13]. Lomas J, Haynes R.B. (1987). A taxonomy and critical review of tested strategies for the application of clinical practice recommendations: from "official" to "individual" clinical policy. Am J Prev Med; 4:77-94.

[14]. Mosby's Medical Dictionary, $8^{\text {th }}$ edition (2009) Elsevier.

[15]. Mugford M, Banfield P, O'Hanlon M. (1991). Effects of feedback of information on clinical practice: a review. BMJ;303:398-402

[16]. Norris, S. P. \& Ennis, R.H. (1989). Evaluating critical thinking. Pacific Grove, CA: Midwest Publications, Critical Thinking Press

[17]. Nutt, A. (2009) Challenges Facing Nurse Practitioners. Retrieved September 13, 2010 from http://ezinearticles.com/? ChallengesFacing-Nurse-Practitioners \& id $=2514413$

[18]. Oermann, M.H., \& Gaberson, K. (1998). Evaluation and testing in nursing education. New York: Springer.

[19]. Paul, R., \& Heaslip, P.(1995). Critical thinking and intuitive nursing practice. Journal of Advanced Nursing Practice, 22, 40-70.

[20]. Paul, R.W. (1990). Critical thinking: What every person needs to survive in a rapidly changing world. Rohnert Park, California: Center for Critical Thinking and Moral Critique

[21]. Registered Nurse's Association of British Columbia, 1990

[22]. Roter, D., Frankel, R. M., Hall, J. A. \& Sluyter, D. (2006). The expression of emotion through nonverbal behaviour in medical visits; mechanisms and outcomes. Journal of GEN INTERN MED, 21:S28 - 34

[23]. Smith, R. (2008). What is competency in nursing? Retrieved on $20^{\text {th }}$ July 2011 from http://www.approvedarticles.com

[24]. Veronica, D., Ernest, A., Eric, O. \& Duah, O. K. (2011). Client satisfaction with out-patient care, A study at St. Michael's Hospital, Ghana. West African Journal of Nursing, 22(2): 83 - 94

[25]. Watson, G., Glaser, E. M. (1980). Watson-Glaser critical thinking appraisal manual. San Antonio: The Psychological Corporation: Harcourt Brace Jovanovich, Inc.

[26]. Wolff, L., Weitzel, M. H. and Fuerst, E. (1979). Fundamentals of Nursing, Philadelphia: J. B. Lippincott Co. 